\title{
Optical properties of $p$-type porous GaAs
}

\author{
V.V. Kidalov ${ }^{1}$, L. Beji ${ }^{2}$, G.A. Sukach ${ }^{3}$ \\ ${ }^{1}$ Berdyansk State Pedagogical University, 4, Shmidt str., 71100 Berdyansk, Ukraine \\ phone: +38 (06153) 63373; e-mail: kid@bdpu.org, \\ ${ }^{2}$ Laboratoire de Physique et de Chimie des Interfaces, Faculté des Sciences 5019 Monastir, Tunisia \\ ${ }^{3}$ Institute of Semiconductor Physics, NAS of Ukraine, 45, prospect Nauky 03028 Kyiv, Ukraine
}

\begin{abstract}
Samples of $p$-type porous GaAs was obtained by electrochemical anodization of (100) oriented $p$-type GaAs. The formation of porous structure has been confirmed by Raman spectroscopy and scanning electron microscopy investigations. The lowfrequency Raman shift of the peaks conditioned by the main optical phonons was observed in the Raman spectra of the porous GaAs. Estimation of the size of nanocryslallites in porous GaAs both by Raman shift and scanning electron microscopy gives approximately the same values and was about 10-20 nm. Photoluminescence investigations of porous GaAs exhibit the presence of two infrared and one visible bands.
\end{abstract}

Keywords: porous GaAs, quantum confinement, electrochemical etching, photoluminescence, scanning electron microscopy.

Manuscript received 28.09.05; accepted for publication 25.10.05.

\section{Introduction}

At present time, sapphire $\left(\mathrm{Al}_{2} \mathrm{O}_{3}\right)$ has been mainly used for epitaxial growth of $\mathrm{GaN}$ films. But $\mathrm{GaN} / \mathrm{Al}_{2} \mathrm{O}_{3}$ structures are characterized by a high value of strains due to a significant difference in their thermal expansion coefficient and lattice mismatch between the substrates and epitaxial films. Strains lead to a high density of dislocations and significant worsening the optical and mechanical properties of GaN films. Recently, extensive scientific and technological researches were performed to diminish residual strains in GaN films on different foreign and "native" $\mathrm{GaN}$ substrates ( $\mathrm{SiC}, \mathrm{Si}, \mathrm{GaAs}$, $\mathrm{GaN}$, etc.) [1-3]. Porous GaAs attracts attention in recent years as a promising substrate for GaN epitaxy, for the purpose of minimizing some negative effects due to large lattice mismatch and difference in the thermal expansion coefficient of GaAs and GaN, which usually leads to high strains and the high defect density in $\mathrm{GaN} / \mathrm{GaAs}$ structures. Among the first attempts of using porous $\mathrm{GaAs}$ as a substrate for $\mathrm{GaN}$ epitaxy, it was reported in [4-6]. Earlier [7], we reports about properties of cubic $\mathrm{GaN}$ films obtained by nitridation of porous GaAs (001). Now formation of porous GaAs p-type attracts significant attention, hitherto there are few reports of obtaining the porous structure on a GaAs substrate of the $p$-type (for example, [8]). In this work, we reports on the optical properties of $p$-type porous GaAs by using Raman spectroscopy and photoluminescence (PL).

\section{Experimental}

Porous GaAs was produced by electrochemical anodization of (100)-oriented p-type GaAs substrate doped with $\mathrm{Zn}$, having the carrier concentration approximately $6 \times 10^{17} \mathrm{~cm}^{-3}$. The sample was electrochemically anodized in a HF-based solution under galvanostatic conditions. The electrochemical anodization conditions were: HF-EtOH (1:3) was used as the as electrolyte, the current density was set at $8 \mathrm{~mA} \cdot \mathrm{cm}^{-2}$ and the anodization time was $60 \mathrm{~s}$. Prior to each experiment, the samples were degreased with acetone, propanol, methanol and extensively rinsed with deionized water and were then blown dry in $\mathrm{N}_{2}$. Electric contact to the samples was established by smearing GaIn eutectic onto the backside of cleaved samples. The samples were then pressed against an o-ring in Teflon electrochemical cell, with a platinum working electrode. The microstructure of the as-prepared porous GaAs layer was studied using scanning electron microscope (SEM), Raman spectroscopy and PL. Raman spectra were obtained using a double monochromator ДФС-24. The samples were excited with $488 \mathrm{~nm}$ line of an $\mathrm{Ar}^{+}$laser with the power of $100 \mathrm{~mW}$.

\section{Results and discussion}

\subsection{Scanning electron microscopy}

SEM was used to investigate the por-GaAs layers surface. From Fig. 1a, we observe pores having the form 

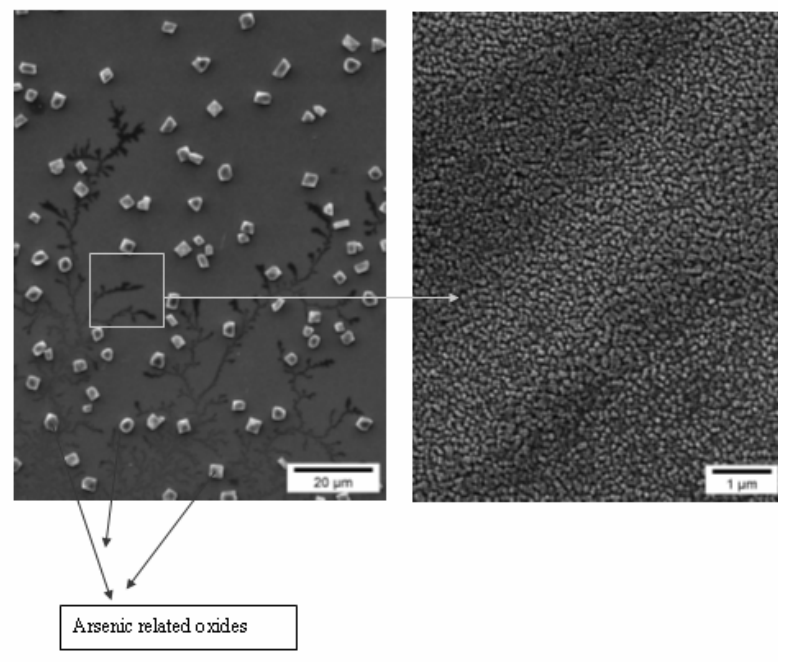

Fig. 1. SEM images of a) the top view of as-prepared porous GaAs, b) higher magnification view of the region inside the square of (a).

of the labyrinth, as well as crystallites of GaAs. On the surface of por-GaAs, diamondlike $\mathrm{As}_{2} \mathrm{O}_{3}$ crystallites were observed (Fig. 1a). Analysis of the SEM image (Fig. 1b) obviously demonstrates that the GaAs substrate was formed into the porous structure. From SEM investigations, the average size of GaAs nanocrystallites was estimated within the range $15-25 \mathrm{~nm}$.

\subsection{Raman spectroscopy}

Treatment of porous GaAs in $\mathrm{H}_{2}$ ambient was used to remove residual chemical reaction products formed on the GaAs surface during electrochemical processing. The estimation of the average diameter of $\mathrm{GaAs}$ nanocrystallites was made using the shift value of the Raman peak, the shift is due to longitudinal optical (LO) phonons of GaAs. Fig. 2 shows Raman spectra for the

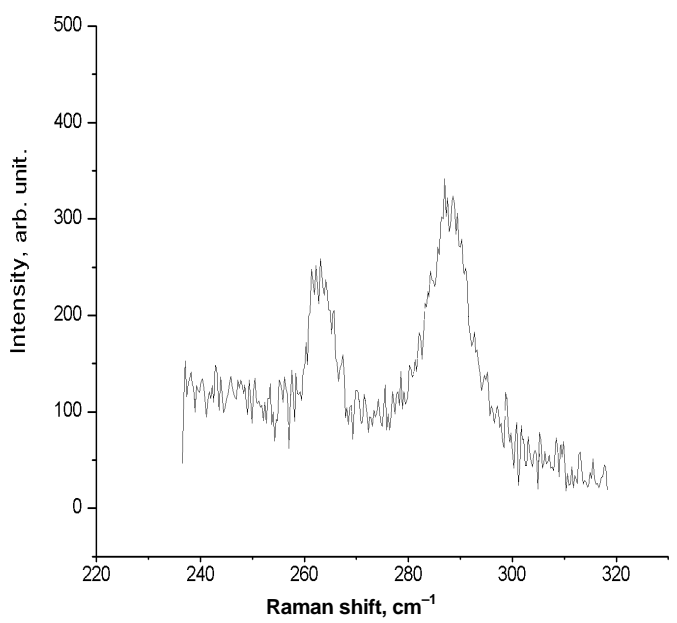

Fig. 2. Raman spectra of porous GaAs (sample with the maximum value of the peak shift). sample of por-GaAs with the maximum shift value. From the obtained data, we estimated the average size of GaAs nanocrystallites, as described in [9], its value is about $8 \mathrm{~nm}$.

\subsection{Photoluminescence measurements}

Fig. 3.1 shows PL spectra (at $77 \mathrm{~K}$ ) of initial GaAs (a) and por-GaAs (b). There are no shift to the shorter wavelengths for the peak at $833 \mathrm{~nm}(1.49 \mathrm{eV})$ of por$\mathrm{GaAs}$, as it was reported for the similar peak in [10]. We associated this peak with quasi-interband transition in the initial mono-GaAs substrate. Also, the peak at $903 \mathrm{~nm}(1.37 \mathrm{eV})$ was observed, its presence is scarcely noted for porous GaAs of the p-type except for [8], where this peak (with a much less intensity) was also observed. We associate it with significant fluctuations of conduction and valence band extrema due to layer porosity.
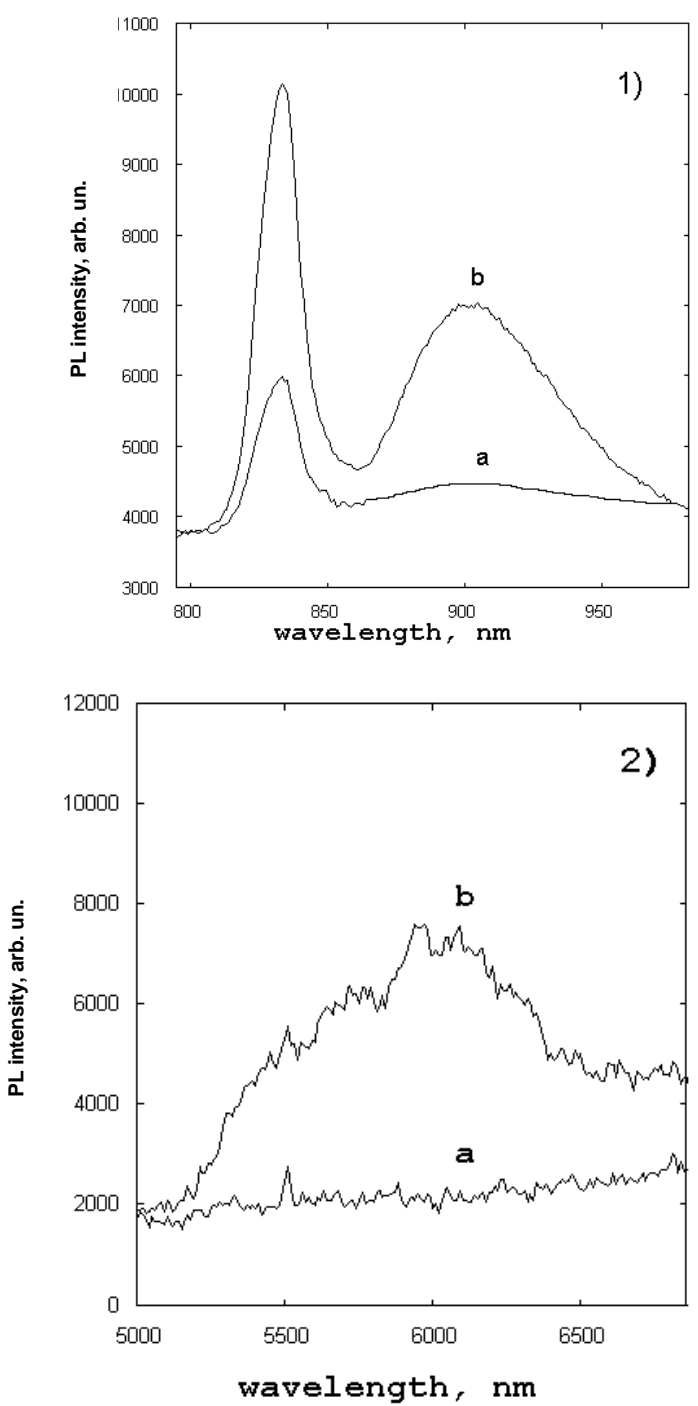

Fig. 3. $77 \mathrm{~K}$ Photoluminescence spectra of : a) initial GaAs, b) porous GaAs. 
Beside peaks at 833 and $903 \mathrm{~nm}$, the broad line in the visible region (peaking approximately at $600 \mathrm{~nm}$ ) was observed for por-GaAs, the so-called yellow PL (Fig. 3.2), which indicates formation of GaAs differentsized cluster at electrochemical etching, a) - initial GaAs, b) - por-GaAs. The similar data for visible PL were presented in [11]. There are two basic assumption of the origin of visible PL in por-GaAs. The first explanation implies that the band in the visible region of photoluminescence is caused by residual products of the chemical reaction in the cause of etching (oxides $\mathrm{Ga}_{2} \mathrm{O}_{3}$, $\mathrm{As}_{2} \mathrm{O}_{3}$ ) [7]. The second assumption associates visible PL with quantum confinement effects due to nano-sized GaAs crystallites [12]. The average size of GaAs nanocrystallites was calculated from PL measurements, its value was about $10 \mathrm{~nm}$.

We suppose that oxides has no considerable contribution to the origin of visible PL in porous GaAs inasmuch as after electrochemical etching the samples were treated in $\mathrm{H}_{2}$ ambient. XPS measurements show that such treatments lead to a significantly decreasing intensity of the oxides signal, as was reported earlier [10]. On the other hand, comparison of the position of PL peak in the visible spectral range (for porous GaAs) and that of GaAs nanocrystal [13] let us consider that quantum confinement effects prevail in origin of the band in visible PL.

\section{Conclusion}

From PL measurements of por-GaAs, the average size of GaAs nanocrystallites was determined, its value is about $10 \mathrm{~nm}$. The distinctive features of presented PL spectra is the broad intensive band with the peak at $903 \mathrm{~nm}$, which is typical for $p$-type por-GaAs. The broad PL band in the visible range indicates the presence of GaAs nanocrystallites on por-GaAs. From Raman spectroscopy, the average value for GaAs nanocrystallites was estimated, it was about $8 \mathrm{~nm}$. PL and Raman investigation are in a good agreement in a view of calculations for GaAs nanocrystallites. Morphology of por-GaAs surface was investigated by scanning electron microscopy, calculation of the size of GaAs nanocrystallites gave the value of $15-25 \mathrm{~nm}$. The difference in values of nanocrystallite sizes obtained from PL, Raman, on the one hand, and SEM investigations, on the other hand, can be explained as the presence of oxide layers on por-GaAs surface that in its turn led to the increasing visible size of GaAs nanocrystallites.

\section{Acknowledgements}

This work performed under the financial support of SFFI of Ukraine, grant 04.07/256.

\section{References}

1. A. Missaoui, M. Saadoun, H. Ezzaouia, B. Bessaïs, T. Boufaden, A. Rebey, B.E. Jani, Growth of GaN Films on porous silicon by MOVPE // Phys. status solidi (a) 18(1), p. 189-193 (2000).

2. T. Boufaden, A. Matoussi, S. Guermazi, S. Juillaguet, A. Toureille, Y. Mlik, B.E. Jani, Optical properties of GaN grown on porous silicon substrate // Phys. status solidi (a) 201(3), p. $582-587$ (2004).

3. C.K. Inoki, T.S. Kuan, A. Sagar, C.D. Lee, R.M. Feenstra, D.D. Koleske, D.J. Diaz, P.W. Bohn, I. Adesida, Growth of $\mathrm{GaN}$ on porous $\mathrm{SiC}$ and GaN substrates // Phys. status solidi (a) 200(1), p. 44-47 (2003).

4. V.V. Kidalov, G.A. Sukach, A.S. Revenko, E.P. Potapenko, Ultraviolet luminescence of GaN thinfilms grown on porous $\mathrm{GaAs}(111)$ substrates by radical-beam getering epitaxy // Semiconductors 37, p. 1264-1266 (2003).

5. V.V. Kidalov, G.A, Sukach, A.O. Petukhov, A.S. Revenko, E.P. Potapenko, Photoluminescent and structural properties of GaN thin films obtained by radical-beam guttering epitaxy on porous GaAs(001) // Journal of luminescence 102-103, p. 712-714 (2003).

6. V.V. Mamutin, V.P. Ulin, V.V. Tretyakov, Growth of cubic GaN by molecular-beam epitaxy on porous GaAs substrates // Tech. Phys. Lett. 25(1), p. 2-9 (1999).

7. V.V. Kidalov, G.A. Sukach, A.S. Revenko, A.D. ayda, Properties of cubic GaN films by nitridation of porous GaAs (001) // Phys. status solidi (a), 202(8), p. 1668-1672 (2005).

8. L. Beji, L. Sfaxi, B. Ismail, S. Zghal, F. Hassen, H. Maaref, Morphology and photoluminescense studies of electrochemical etched heavily doped $\mathrm{p}$ type GaAs in HF solution // Microelectronics Journal 34, p. 969-974 (2003).

9. A.I. Belogorokhov, S.A. Gavrilov, I.A. Belogorokhov, Structural and optical properties of porous gallium arsenide // Phys. status solidi (c) 2(9), p. $3491-3494$ (2005).

10. S. Langa, J. Carstensen, M. Christophersen, M. Tiginyani, D.R. Turner, Pores in III-V semiconductors // Adv. Mater. 15(3), p. 183-198 (2003).

11. D.J. Lockwood, P. Schmuki, H.J. Labbé, J.W. Fraser, Optical properties of porous GaAs // Physica E: Low-dimensional Systems and Nanostructures 4(2), p. 102-110 (1999).

12. J.J. Kelly, A.C. Reynders, A study of GaAs etching in alkaline $\mathrm{H}_{2} \mathrm{O}_{2}$ solutions // Appl. Surf. Sci. 29(2), p. 149-164 (1987).

13. M. Hao, H. Uchida, C. Shao, T. Soga, T. Jimbo, M. Umeno, Porous GaAs formed by a two-step anodization process // J. Cryst. Growth 179 (3-4), p. 661-664 (1997). 